\title{
Knowledge about the PCPNDT Act amongst uninitiated medical students and their personal psychological preferences regarding related issues - a cross sectional study from a rural medical college
}

\author{
Harshal Sabane ${ }^{1}$, Aishwarya Agarwal ${ }^{2}$, Bandana Patnaik ${ }^{3}$ \\ ${ }^{1}$ Assistant Professor, \\ ${ }^{2}$ MBBS student, \\ ${ }^{3}$ Professor and Head \\ Department of Community Medicine, MIMER Medical College, Talegaon Dabhade. \\ E-mail-harshalsabane@gmail.com
}

\begin{abstract}
Background: In recent decades, India is waking up from its economic slumber and utilizing its everincreasing population as an engine of a continual economic growth. In the background, however, the masculinization of the sex ratio raises many questions. Studies examining the opinions about these important public health issues amongst medical students have been few and far between. Our study aims to assess the existing level of knowledge and attitude towards these topics in second year medical students. Method: The study was conducted among the second-year students of MBBS in a rural medical college. A schedule consisted of questions regarding the general demographic indicators of the students followed by estimates and perceptions of the existing sex ratio, knowledge about the PCPNDT act, and finally their own preferences regarding related issues.

Results: Out of the 110 students present in the class, 107 gave their consent to participate in the study thus making the participation rate $97 \%$. Fifty-one percent students could correctly identify the current sex ratio as between $900-1000$ females per 1000 males. Fifty-one (48\%) students thought that sex selective abortion is more prevalent in the rural areas and $71(66.4 \%)$ students thought that it is more prevalent in the lower socioeconomic strata. Mann-Whitney $U$ test was insignificant for the difference between the opinions of males and females regarding the prevalence of sex selective abortion. Only a quarter $25(23.4 \%)$ had heard about the PCPNDT act and $8(7.47 \%)$ students could expand the acronym: PCPNDT. Most of students wanted 2 children for themselves and the most preferred spacing duration was 3 years. Males students prefer less spacing as compared to females and this was found to be statistically significant with $p=0.014$.

Conclusion: The awareness of the illegality of pre-conceptional and pre-natal sex selection techniques is found to be almost universal. Statistically significant differences were not observed between males and females on the awareness of the act or their perception of areas where sex selection is more prevalent. The outlook of people regarding the trend of sex ratio and the success of PCPNDT act remains pessimistic. Further research is needed for eliciting the perception of the medical students regarding the act and the trends of sex ratio in India.
\end{abstract}

Keywords: PCPNDT Act, sex selective abortion, sex ratio, psychological.

(Paper received $-6^{\text {th }}$ December 2016, Peer review completed $-20^{\text {th }}$ December 2016, Accepted $-28^{\text {th }}$ December 2016) 


\section{INTRODUCTION}

In recent decades, India is waking up from its economic slumber and utilizing its ever-increasing population as an engine of a continual economic growth. In the background, however, the masculinization of the sex ratio raises many questions [1-2]. The natural sex ratio in a population typically ranges from 950 to 970 females per 1000 males [3-4]. The 2011 census figure of the India sex ratio is 940 females / 1000 males [5-8]. It is worth mentioning here that, as with most other health related indicators and indices, the distribution of the sex ratio across various states in India is far from uniform. The current sex ratio is generated by a mixture of some healthy and many unhealthy component State sex ratios.

The sex ratio in Maharashtra expressed as number of females per 1000 males went down from 934 in 1991 census to 922 in 2001. It has shown a minor improvement in the latest census of 2011 where it stood at 925 [5]. The national Pre-Conception and Pre-Natal Diagnostics Techniques (PCPNDT) Act of 1994, implemented in 1996, banned sex-selective abortions in the Indian States, which hitherto had not legislated such a policy [9-12]. In the absence of the legislation it is possible that the child sex ratio would have dropped by another 13-20 points. This translates into the loss of additional 51000 female fetuses per year [1].

There have been numerous studies on the perceptions and knowledge about the sex ratio and the PCPNDT Act in the recent past $[2-4,10]$. However, studies examining the opinions about these important public health issues amongst medical students have been few and far between. Their outlook towards this social reality, which is intermingled with the field of medicine, is vital for their early sensitization. Our study aims to assess the existing level of knowledge and mental attitude towards these topics in second year medical students.

\section{METHODOLOGY}

This cross-sectional study was conducted in the last quarter of 2015 in a rural medical college in the Pune district of Maharashtra state in India. Students of the second year nearing the end of their first term were invited to participate in the study.

Sample size was calculated using the formula $\mathrm{n}=4(\mathrm{pq} / \mathrm{L} 2)$ where $\mathrm{p}=$ population proportion of positive character, $\mathrm{q}=1-\mathrm{p}$ and $\mathrm{L}=$ Allowable Error. For this study, $\mathrm{L}$ was presumed to be $10 \%$ of $\mathrm{p}$ giving a power of (1-L) i.e. $90 \%$ to study. With a very conservative estimate of $50 \%$ awareness, based on the various studies on similar populations, the sample size was 100 .

Permission for the conduct of the study was obtained from the Ethics Committee of the institution. The students were explained the objective of the study along with the importance of their feedback and opinion regarding the topic under consideration. Written consent for participation was taken prior to the commencement of data collection. A pre-designed self-administered print schedule was distributed among the students in the class. Before the students commenced answering, each question was read out and explained to the class. The pen-and-paper research tool consisted of questions regarding the general demographic indicators of the students followed by estimates and perceptions of the existing sex ratio, knowledge about the PCPNDT act, and finally their own preferences regarding related issues.

\section{STATISTICAL ANALYSIS}

The data was tabulated in Microsoft Excel 2010 and exported and analyzed in SPSS version 21.0 Categorical variables were analyzed by Chi square test. For non-parametric variables, Mann-Whitney's U test was applied.

\section{RESULTS}

Out of the 110 students present in the class, 107 gave their consent to participate in the study thus making the participation rate $97 \%$. 
Table 1 - Distribution of the students according to basic demographic variables

\begin{tabular}{|lll|}
\hline Age & Frequency & \% \\
\hline 18 & 19 & 17.8 \\
\hline 19 & 58 & 54.2 \\
\hline 20 & 21 & 19.6 \\
\hline 21 & 4 & 3.7 \\
\hline Info. Missing & 5 & 4.7 \\
\hline Sex & & \\
\hline Males & 46 & 43.0 \\
\hline Females & 56 & 52.3 \\
\hline Info. Missing & 5 & 4.7 \\
\hline
\end{tabular}

Most participants 104 (94.4\%) were aware that sex ratio used most frequently in India was the number of females per 1000 males. Fifty-three (51\%) of the students correctly estimated that the current sex ratio in India lies between 900 - 1000 females / 1000 males. Only 1 student had a highly optimistic estimate of the sex ratio. When asked about where the practice is found to be most prevalent,51 (48\%) students thought that it is more prevalent in the rural areas. Only16 (15\%)thought the practice prevalent in urban areas while 31 (29\%)thought it was equally prevalent.

Seventy-one (66.4\%) students thought that sex selective abortion is more prevalent in the lower socioeconomic strata while only $12(11.2 \%)$ students thought it more amongst higher socioeconomic strata. When the gender distribution of this opinion was tested by the independent samples Mann-Whitney $\mathrm{U}$ test, the difference between the opinions of males and females regarding the prevalence of sex selective abortion was found to be insignificant with a $p$ value of 0.075 .

Only $40(38.8 \%)$ of students were aware that the sex ratio in India has been increasing over the past two decades. The general opinion regarding sex ratio is that it is dismal in India and plummeting every passing decade. The same opinion is reflected in the study where $67(61.2 \%)$ of the students thought that the sex ratio is either decreasing or stable.

Figure 1 - Proportion of students opining about the state with the worst state ratio compared against the actual sex ratio of each state

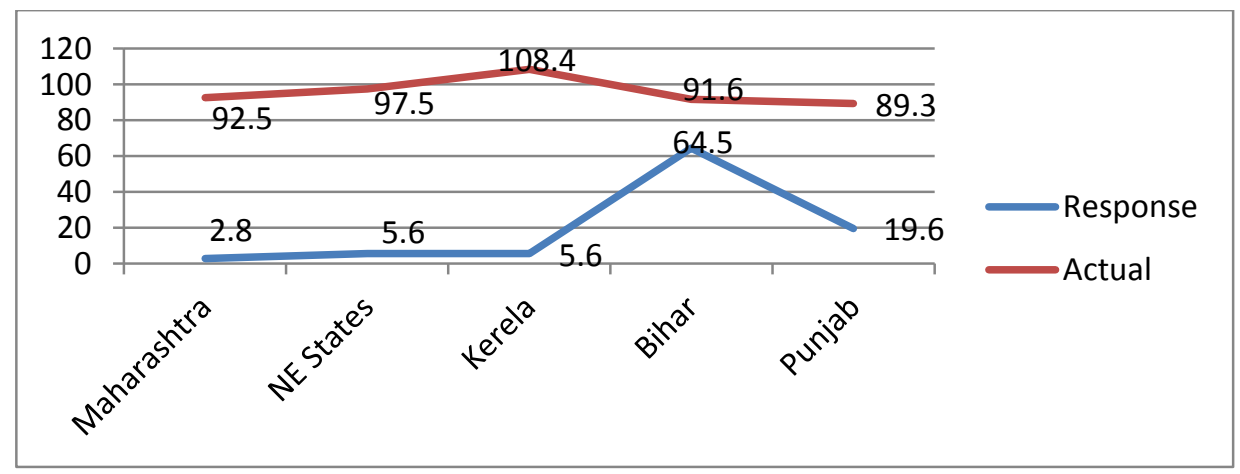

The graph above shows the opinion of the students when asked about which of the States given in the options has lowest sex ratio. The graph plots student's responses in percentages in contrast with the actual sex ratios of the States converted to the number of females / 100 males for plotting on a single axis. 69 $(64.5 \%)$ of the students wrongly believe that Bihar has the worst sex ratio. 
Table 2 - Findings regarding the awareness of PCPNDT Act and its related attributes

\begin{tabular}{|lllll|}
\hline & Yes (\%) & No (\%) & Don't Know (\%) & Total (\%) \\
\hline $\begin{array}{l}\text { Have you heard about } \\
\text { PCPNDT Act }\end{array}$ & $25(23.4)$ & $82(76.6)$ & NA & $107(100)$ \\
\hline $\begin{array}{l}\text { What is thefull form of } \\
\text { PCPNDT Act }\end{array}$ & $8(7.47)$ & $99(92.52)$ & NA & $107(100)$ \\
\hline $\begin{array}{l}\text { Is pre-natal sex } \\
\text { determination } \\
\text { punishable }\end{array}$ & $102(96.2)$ & $2(1.9)$ & $2(1.9)$ & $106(100)$ \\
\hline $\begin{array}{l}\text { Do you know that } \\
\text { Doctors have been } \\
\text { convicted }\end{array}$ & $18(18.4)$ & $80(81.6)$ & NA & $98(100)$ \\
\hline
\end{tabular}

In spite of extensive advertisement of the PCPNDT Act as well as sensitization efforts directed at the public, our survey found that only a quarter $25(23.4 \%)$ had heard about the act. Unsurprisingly then, only $8(7.47 \%)$ students could expand the acronym: PCPNDT. Although the students had not heard the act by its name, almost all $102(96.2 \%)$ were aware that pre-natal sex determination was a punishable offence.

Amongst the students who knew that pre-natal sex selection is an offence, responses were analyzed for the question of who do you think should be punished in cases of pre-natal sex determination. Most of the students i.e. $85(83 \%)$ opined that both the doctor as well as the patients seeking gender identification should be held guilty.

Table 3 - Gender wise distribution of awareness about PCPNDT Act

\begin{tabular}{|lllll|}
\hline Gender of student & \multicolumn{3}{l}{ Awareness of PCPNDT Act } \\
\cline { 1 - 4 } & Yes (\%) & No (\%) & Total (\%) & Statistics \\
\hline Male & $15(14.71)$ & $31(30.39)$ & $46(45.10)$ & $\begin{array}{l}\mathrm{x}^{2}=3.83, \\
\mathrm{df}=1, \\
\mathrm{p}=0.05\end{array}$ \\
\cline { 1 - 4 } Female & $9(8.82)$ & $47(46.08)$ & $56(54.90)$ & \\
\cline { 1 - 3 } & $24(23.53)$ & $78(76.47)$ & $102(100)$ & \\
\hline
\end{tabular}

Among the male students $15(32.60 \%)$ had heard about the PCPNDT act whereas among the female students only $9(16.07 \%)$ were aware of it. However, this difference was not statistically significant.As 5 students, had failed to mention gender in their responses, those students were not included in this analysis.

Figure 2 - Preferred number of children by medical students

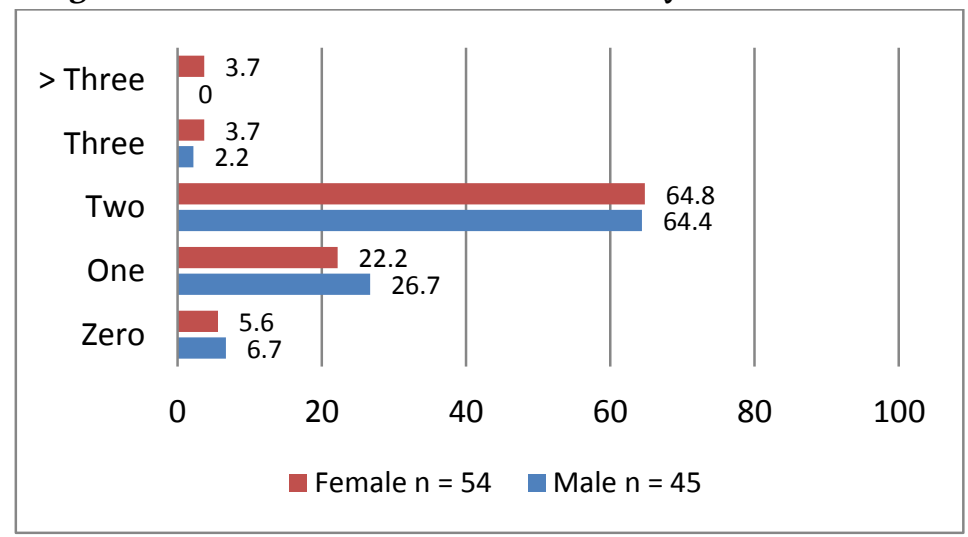


The graph for number of children the medical students themselves would like to have, split by the gender of the responder, shows almost identical bars for each option. The most popular response for 29 (64.4\%) male students as well as for 35 (64.8\%) female students was two.

Table 4 - Preferred gender of the child

\begin{tabular}{|lllll|}
\hline Students & None (\%) & Male (\%) & Female (\%) & Total (\%) \\
\hline Male students & $42(93.33)$ & $1(2.22)$ & $2(4.44)$ & $45(100)$ \\
\hline Female students & $48(88.88)$ & $1(1.85)$ & $5(9.25)$ & $54(100)$ \\
\hline \multicolumn{5}{c}{$\left(x^{2}=0.875, \mathrm{df}=2, \mathrm{p}=0.646\right)$}
\end{tabular}

Only $9(10 \%)$ students out of the $99(100 \%)$ responders had a preference for a male or female child. Since the total number of responders having a gender preference was miniscule as compared to responders with no preference, the chi square test expectantly was not significant.

Figure 3 - Medical students' preferred spacing among children

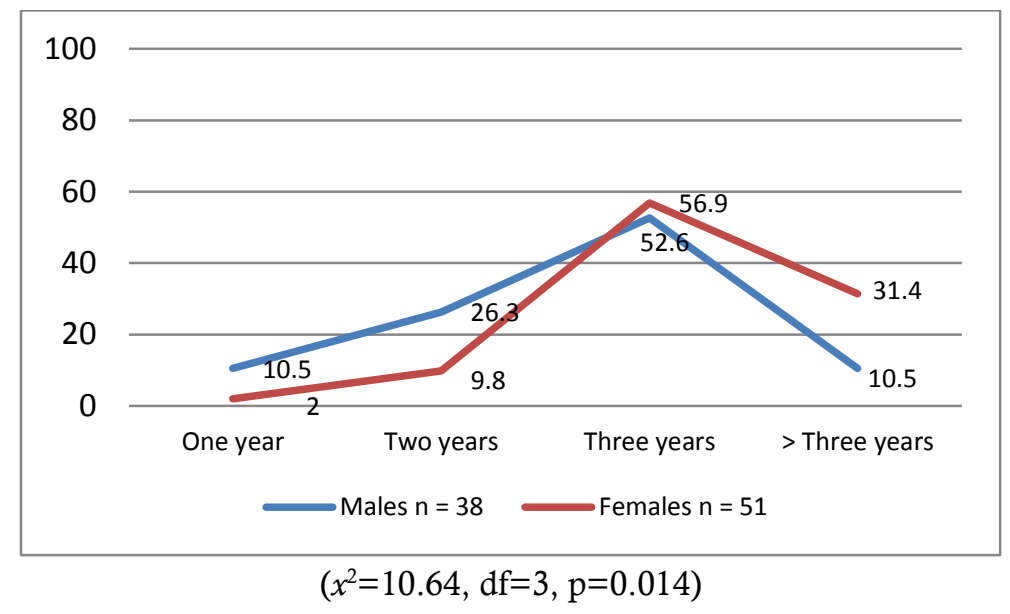

Male students were willing to have a lesser spacing in between their children while the female students wanted to have increased duration between two childbirths. The difference is statistically significant. The most common spacing desired by both genders was 3 years.

Out of the 104 student responders, 100 (96.2\%) said they do not wish to know the sex of their unborn child. This high percentage of students responding in the negative would have been caused by the overall sensitization of the public about the issues surrounding sex selective abortion and the hirsute Indian sex ratio. The proportion of boys and girls who would want to know the gender of their unborn baby is the same. On similar lines 103 (96.2\%) students, did not support sex selective abortions. The support for sex selective abortion rises abruptly to $76(71.0 \%)$ should the fetus be at a risk of congenital anomaly.

\section{DISCUSSION}

In most countries, sex determination of the fetus would not raise a frown. Most of the ante-natal centers on their own volition disclose the gender of the baby to the prospective parents [13]. However, in times of the skewed sex ratio of our country, it has become a rule to hide this information from the parent.

Since the students were uninitiated in the subject of the study, it would be safe to assume that their knowledge regarding this topic would parallel that of students of any other faculty and well educated youth in general. Almost everybody knew about the worrisome sex ratio in India. The practice of sex selective abortion is prevalent in all parts of the country transcending the urban-rural and educateduneducated boundaries. However, almost a half of the students believed that it is predominantly a rural 
problem. This finding is similar to many other studies done on this topic on comparable populations [6, 79]. In a study conducted in a teaching institute in Mumbai, $98 \%$ of the medical students were aware of the adverse sex ratio [6]. Sex ratio is steadily increasing in India since the last two decades however this trend is not true for all the States [5]. Our study explored the perception of the trend in the national sex ratios and found that contrary to fact, many students are pessimistic about the current trend. It would be inquisitive for other authors to study this further.

More than half of the students were of the opinion that Bihar has got the worst sex ratio among the options that were presented to them. Actually, Punjab has the worst sex ratio with only 893 girls / 1000 males according to the census of the year 2011 [12].

The awareness of the message of the PCPNDT was found to be almost universally present however the awareness of the act was not so widespread with only a quarter knowing about it. The awareness of the adverse sex ratio was evident in almost everybody. This is higher in comparison to the findings of other studies [14-16].

Most of the students 77 (72\%) were aware of other methods of sex selection. This is comparable to the findings of other researchers [11]. It is highly variable in other studies [16-18] due to the fact that all medical colleges are not equal. The student profile opting for each is different and therefore their background knowledge may vary. Our study is limited by the fact that students of a single academic year were included in the study. As the curriculum progresses further, the students are expected to better their awareness of the act including its prescribed penalties. A study done with senior batches can yield a comparison of the knowledge in between those batches. Although the response rate for most of the items on the study tool was satisfactory, many students did not reveal information regarding their parents being doctors. Analysis based on this factor hence had to be abandoned.

\section{CONCLUSION}

Although the students are not aware of the PCPNDT act by its name, the awareness of the illegality of preconceptional and pre-natal sex selection techniques if found to be almost universal. Statistically significant differences were not observed between males and females on the awareness of the act or their perception of areas where sex selection is more prevalent. Most of the students, for themselves, want two children with male students eager to become fathers earlier as compared to the females wanting to become mothers. The PCPNDT act is showing its effect on its intended statistic. The outlook of people regarding the trend of sex ratio and the success of PCPNDT act remains pessimistic. Further research is needed for eliciting the perception of the medical students regarding the act and the trends of sex ratio in India.

\section{REFERENCES}

1. Nandi A, Deolalikar A. Does a Legal Ban on Sex-Selective Abortions Improve Child Sex Ratios? Evidence from a Policy Change in India. J Dev Economics 2013;3:1-4

2. Patel V. Sex-determination and sex preselection tests in India: recent techniques in femicide. Reprod Genet Eng 1989;2:111-9.

3. George SM. Millions of missing girls: from fetal sexing to high technology sex selection in India. Prenat Diagn 2006;7:604-9.

4. Oomman N, Ganatra BR. Sex selection: the systematic elimination of girls. Reprod Health Matters 2002;10:184-8.

5. http://www.censusindia.gov.in/2011census/population_enumeration.html [Internet]. New Delhi. The Registrar General \& Census Commissioner, India, New Delhi, Ministry of Home Affairs, Government of India. Cited $12^{\text {th }}$ April 2016. Available from: http://www.censusindia.gov.in

6. Patil S, Singh V, Chavan S, Gadkari M, Chaturvedi RM. Knowledge and attitude regarding PCPNDT act among medical undergraduates: a study conducted in teaching institute Mumbai. Innov J Med Health Sci 2014;4:83-5.

7. Avchat S, Raut P, Zambare M, Gund D, Pundkar R. Perspectives of Medical Interns Regarding Female Feticide and Declining Sex Ratio in India. N Am J Med Sci. 2013:8:469-72. 
8. Shalini S, Karival P, Kapilasrami MC. A community-based study on awareness and perception on gender discrimination and sex preference among married women (in reproductive age-group) in a rural population of district Bareilly Uttar-Pradesh. Natl J Comm Med 2011;2:273-6.

9. Palo LB, Chauhan NS, Parvathi T, Chauhan RC. Awareness about PCPNDT act among undergraduate students of a medical college in Puducherry. Int J Reprod Contracept Obstet Gynecol 2015;5:1485-88.

10. Mitra PS, Dasgupta M, Banerjee P, Soreng P, Shirazee SS, Adhikari S. A Study On Preferences and Awareness Regarding Prenatal Sex Determination Among Antenatal Women Attending Obstetrics and Gynecology Outdoor Of Medical College, Kolkata During The Time Period Of January To June, 2012. IOSR J Dent Med Sci 2013;6:100-4.

11. Deshpande SR, Rathod PG, Mankar SB, Narlawar UW. Awareness and perception regarding PCPNDT Act and gender preference among mothers of under-five attending immunization clinic. Int J Med Sci Pub Health 2016;5(9):1878-82..

12. Park K. Demography and family planning. In: K Park, editor. Park's textbook of preventive and social medicine, $23^{\text {rd }}$ edition. Jabalpur: Banarsidas Bhanot publishers; 2015.

13. Lingam L. Sex-detection tests and female foeticide: discrimination before birth. Indian J Soc Work. 1991;52:13-20.

14. Singh R, Verma R, Dixit P, Saini M, Singh A, Chawla S. Awareness about female feticide among adolescents in rural areas of Haryana: a school based cross-sectional study. International Journal of Basic and Applied Medical Sciences 2015;5:71-7.

15. Kumar N, Darshan BB, Unnikrishnan B, Kanchan T, Thapar R, Mithra P. Awareness and Attitudes Regarding Prenatal Sex Determination, Pre-Conception and Pre-Natal Diagnostic Techniques Act (PCPNDTA) among Pregnant Women in Southern India. J Clin Diagn Res 2014;8:9-11.

16. Shidhaye PR, Giri PA, Nagaonkar SN, Shidhaye RR. Study of knowledge and attitude regarding prenatal diagnostic techniques act among the pregnant women at a tertiary care teaching hospital in Mumbai. J Educ Health Promot 2012;1:36-45.

17. Yasmin S, Mukherjee A, Manna N, Baur B, Datta M, Sau M et al. Gender preference and awareness regarding sex determination among antenatal mothers attending a medical college of eastern India. Scand J Public Health 2013;41:344-50.

18. Kansal R, Maroof KA, Bansal R, Parashar P. A hospital-based study on knowledge, attitude and practice of pregnant women on gender preference, prenatal sex determination and female feticide. Indian J Public Health 2010;54:209-12.

Acknowledgements - The authors would like to thank Dr. Alka Sontakke, Principal MIMER Medical College for granting us the permission to conduct the study. Dr. Chandrashekhar Apte, Associate Professor, Department of Human Function, Oman Medical College has helped in extensively revising and correcting the original manuscript of the research.

Source of Funding - Nil

Conflict of Interest - The authors have no conflict of interest to declare 